\title{
Secondary teachers' perspectives on sustaining growth mindset concepts in instruction
}

\author{
Maria Jorif and Cheryl Burleigh \\ College of Doctoral Studies, University of Phoenix, Phoenix, Arizona, USA
}

\begin{abstract}
Purpose - The purpose of this paper is to explore perspectives of secondary (9-12) teachers on how to sustain growth mindset concepts within instructional practices as well as identifying barriers to sustainment.

Design/methodology/approach - This study employed an exploratory case study to obtain the lived experiences of participants. An inductive analysis process was utilized on the data collected through structured interviews and a semi-structured focus group.

Findings - Four major themes emerged from an in-depth analysis process: embed growth mindset practices in daily classroom instruction, communicate verbal affirmations and implement growth mindset learning tasks, allow students to experience academic successes and failures and teachers should receive continual support. Research limitations/implications - The study was limited to secondary grades (9-12). Therefore, it is recommended to expand the study to grades $K-8$.

Originality/value - Due to a gap in the literature, this study provided insights into sustaining an innovative psychological approach, growth mindset, within academic instruction. Growth mindset concepts have been supported through the work of seminal researcher Carol Dweck and other prevalent educational researchers (e.g. Robert Marzano) to provide teachers with effective classroom instructional practices that can academically progress students.
\end{abstract}

Keywords Instruction, Education, Academic progression, Effort(s), Mindset (growth and fixed)

Paper type Case study

\section{Introduction}

Educators are obliged to create an innovative, positive, continual changing, learning environment "to ensure quality preparation of all students to life and work" (Serdyukov, 2017, p. 4). An educator's responsibility is to pursue those innovative instructional tools that may have had effective results in sustaining the progression of students academically (Ragland, 2015). Educators who are willing to align their way of thinking to meet the academic needs of students provide relevant opportunities for academic successes (de Kraker-Pauw et al., 2017). The sustainment of growth mindset practices in instruction, which is a psychological approach for positive continual academic change (Paunesku et al., 2015), can be considered as an innovative instructional practice needed to support the advancement of student academics.

Seminal research surrounding the development of growth mindsets astounded the field of education in the early 2000s (Dweck, 2018). Views of personal capabilities to facilitate the progression of learning were established through mindsets (Robinson, 2017). Two recognized forms of mindset emerged: fixed (stagnate perception of abilities) and growth (malleable

(C) Maria Jorif and Cheryl Burleigh. Published in Journal of Research in Innovative Teaching \& Learning. Published by Emerald Publishing Limited. This article is published under the Creative Commons Attribution (CCBY 4.0) licence. Anyone may reproduce, distribute, translate and create derivative works of this article (for both commercial and non-commercial purposes), subject to full attribution to the original publication and authors. The full terms of this licence may be seen at http://creativecommons. org/licences/by/4.0/legalcode.

The authors thank the Center for Educational and Instructional Technology Research, College of Doctoral Studies, University of Phoenix, for supporting the preparation of this article.

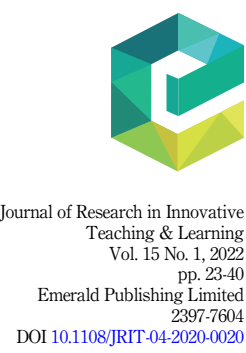

Received 15 April 2020

Revised 16 August 2020 Accepted 12 September 2020 
JRIT

15,1

perception of abilities) (Dweck, 2018). Although one mindset may be practiced predominately by an individual, it is not uncommon to partake in both mindsets. Individuals may continually practice both fixed and growth mindsets (Cook and Artino, 2016).

Growth mindsets may influence the decision-making process of students. However, educators may not be able to readily recognize the need for mindset practices in the classroom (de Kraker-Pauw et al., 2017). Educators who choose to ascertain a successful changing academic setting may facilitate an effective instructional learning environment by incorporating principles of growth mindset (Bates, 2016). Educators who develop and sustain a learning environment that incorporates a progressive mindset may establish a culture for academically thriving students (Bates, 2016).

Educators may currently be unsuccessful in sustaining effective learning practices; therefore, student achievement could become dormant in a non-progressive learning environment (Katrein, 2016). Educators who incorporate instruction with growth mindset concepts present their students with opportunities that potentially can allow for continuance of academic growth. Academic growth, as defined by Clemens et al. (2018), is an increase in knowledge gained over a school year that leads to progression in learned skills. Implications of a non-progressive learning environment may arise when students are not exposed to growth mindset instructional practices. Educators can increase academic progression utilizing growth mindset concepts because students needs may be met when implementing instructional practices that include growth mindset practices (Dweck, 2006; 2016).

\section{Problem statement}

Educators have the responsibility to support students' academic progression within a continuously changing academic educational system. In 2015, Every Student Succeeds Act (ESSA) was enacted to provide various learning opportunities to all students to continue to academically thrive (Malin et al., 2017). The significant problem is that there are students who may not be able to maintain their academic progression despite the ESSA requirements due to secondary teachers insufficiently sustaining effective instruction which includes growth mindset practices (Cooper et al., 2015; Moran, 2015).

\section{Review of literature}

\section{Overview of mindset theory}

Students who lack a willingness (learned helplessness) to achieve goals in academics had become an interest to Dweck back in the 1960s (Dweck, 2006, 2016). After years of research in the area of grit and perseverance, and absence thereof, Dweck's research eventually led to the cultivation of mindset theory inclusive of predominant factors from motivation and attribution theories (Dweck, 2018). Mindset theory encompasses motivation and attribution concepts to support the decision-making process (Dweck, 2017).

In the mid-1900s, motivational theory was regarded as the influential reason for progression in positive behaviors that may lead to various achievements (Haque et al., 2014). The motivational theory provided initial insights into achievement because motivational factors are needed to achieve success (Haque et al., 2014). Research in motivation had promoted the idea that motives may influence human behaviors (Schaller et al., 2017). Humans are motivated to tend to their needs and will elicit positive and/or negative actions until their needs have been gratified (Winston, 2016). Human needs are persistent, and these needs influence behaviors that are both extrinsically and intrinsically motivated (Winston, 2016).

Cerasoli et al. (2014) described extrinsic motivation as external incentives that drive behaviors. Two factors that influence extrinsically motivated behaviors are gains and losses 
that relate to rewards and consequences. Extrinsic motivators due to gains and losses of rewards may affect human needs which then influence behaviors (Cerasoli et al., 2014).

Conversely, an oppositional approach to the development of human behavior is intrinsic motivation. Intrinsic motivation refers to behaviors that are influenced by internal desires and developed when needs are met (Liu and Hou, 2018). A connection can be noted between intrinsic motivation and Maslow's hierarchy of needs as both indicate that human needs must be met for motivation to occur (Helbling, 2018). Also, longevity exists for behaviors that were motivated intrinsically (Liu and Hou, 2018). Intrinsic motivation may be driven by interests; once interests are piqued, the onset of enduring motivations occurred followed by exploration and learning (Cerasoli et al., 2014). Thus, intrinsic motivation may be a necessity to encourage transformative behaviors.

Attribution theory provided a cognitive perspective on thought processes (Heider, 1958) which differs from the behavioral perspective of motivational theory (Weiner, 2014). Perceptions and actions are developed through a form of cognitive structure (mental processes to understand information) (Heider, 1958). Heider, attributing seminal information on attribution theory, specified that human beings continually desire to understand the causation of an event (Weiner, 2008). Diverse situations produce outcomes that could be deemed as successes or failures. According to attribution theory, individuals engage in a thought process wanting to distinguish the causation of outcomes. The thought process developed could influence behaviors that are intentional and unintentional (Malle, 2008). Assumptions are made from the acquired thought process to perceive why an occurrence transpired which produces correlated behaviors.

\section{Mindsets}

Motivation and attribution concepts led to the development of Dweck's mindset theory. There are two practices known in mindset theory: fixed and growth. Individuals may predominantly practice a fixed or growth mindset. Those who practice a growth mindset believe that intelligence is malleable, and those who practice a fixed mindset believe that there are limits to the development of intelligence (Dweck, 2017).

The belief in a fixed mindset (limited intelligence) may create an achievement barrier. According to Mofield and Parker-Peters (2018), little to no efforts are achieved when practicing a fixed mindset due to a defeatist attitude. The perception of intellectual ability may influence the amount of motivation put forth to achieve a goal. In addition, a fixed mindset is shaped when ability is judged by the intellect level. Thus, a fixed mindset may be influenced by the success or failure of a goal which is linked to one's already established intellectual abilities (Mofield and Parker-Peters, 2018).

The perception that intelligence is not stagnant and may progress through efforts is recognized as a growth mindset (Rattan et al., 2015). An array of achievements may be accomplished through the practices of a growth mindset (Sisk et al., 2018). Growth mindset posits that intelligence is not based on what had already been developed; rather, growth mindset intelligence is based on how to increase the development. Efforts may be implemented to achieve success. Individuals who incorporate growth mindset practices employ problem-solving methods to achieve progressive results (Sisk et al., 2018).

\section{Mindset in education}

Educators are tasked to prepare students for future endeavors. There are established goals for academic progression stated in national or regional standards, but the field of education continuously confronts barriers to providing students with quality education (Piyaman $e$ t al., 2017). Interventions are needed to address achievement gaps due to various barriers that impede academic progression (Piyaman et al., 2017). Although there have been various
Secondary teachers sustaining growth mindset 
JRIT

15,1 interventions developed for education management, instruction and curriculum to address the gap, no known psychological intervention had been implemented before mindset theory (Paunesku et al., 2015). Mindset theory presented an alternative intervention process for academic achievement and to address the achievement gap.

Educators were made aware of a psychological intervention that may support academic achievement. The education field was introduced to mindset theory in 2006 (Dweck, 2017). The mindset concepts were well received and used to motivate student efforts during instruction so that academic progression could occur. Educational leaders may provide professional development workshops to teachers to acquaint them with mindset theory. Teachers are then able to support students through motivational learning mindset practices. Equipped with psychological strategies to progress student learning, teachers could foster mindsets to cultivate academic growth (Dweck, 2017). One of the first mindset studies provided data showing that students who were practicing growth mindset beliefs were motivated to increase academic efforts (Blackwell et al., 2007). Research studies that included students have provided support for utilizing psychological interventions for student progression (Degol et al., 2018; Strahan et al., 2017). Research for the effects of mindset strategies started to occur in different areas of education (e.g. classroom, online, higher education). The usage of mindset theories progressed within the educational realm because of the positive effects of the mindset strategies.

\section{Mindset concepts in instruction}

Teachers deliver curricular content to students through a selection of instructional practices. Instructional practices are strategies or techniques teachers choose to implement during their lessons to deliver and engage students so that comprehension of the content in the lesson may be achieved (Persky, 2014). There is a multitude of instructional strategies teachers may use to engage students in the content being learned and support the students' academic progression (Armstrong, 2017).

Marzano (2018) provided motivational strategies that have been used by educators to increase student performance. "Deliberate practice" was a term used by Marzano that described when efforts were used to create purposeful academic goals, goals that may motivate students and desired goals that may be achieved (Ellison and Woods, 2016). Marzano used concepts from growth mindset to support and develop educational motivation strategies to keep students engaged in the classroom (Mawer, 2014). In 2009, Marzano proposed growth mindset strategies would include the expectation that all students would be able to achieve at high levels based on individual efforts in the classroom (Marzano, 2009). Interventions that efficiently support progression are continuously used in the educational field. Educators may be able to use concepts found in mindset theory to replace ineffective instructional classroom practices.

Mawer (2014) noted that occurrences of motivational experiences are necessary for teachers to teach and students to learn. Because teachers are held accountable for student learning, they have the choice to utilize mindset theory in their instruction to motivate students to learn. However, before teachers may guide students through mindset processes to motivate student learning, it is highly recommended that teachers should experience the process themselves (Gutshall, 2017).

Research on growth mindset. A study conducted in the medical field compared performances of medical students on surgical tasks after participating in growth mindset interventions (Cook et al., 2019). Some of the growth mindset interventions included brief motivational video clips, short inspirational journal articles, verbal instructions and praise. The results of the study showed that, although the surgical task was rigorous, the succinct growth mindset interventions motivated a significant number of students to perform the 
surgical task successfully. The researchers learned that brief growth mindset interventions may influence immediate learning performances which suggest that additional data be gathered on growth mindset concepts that can further produce a transference and retention of knowledge.

Another research approach that included growth mindset practices in instruction was utilized to motivate female students in math classes. A study was conducted to seek out information on the mindset of high school students relative to achievement in math and science, technology, engineering and mathematics (STEM) classes (Degol et al., 2018). The researchers were able to present data that concluded females who possessed a growth mindset were more likely to be more successful in achieving higher scores in math than males who also had possessed a growth mindset. The researchers deduced that the gender gap in math and STEM would be able to be reduced if females were to establish and practice growth mindsets.

The inclusion of instructional growth mindset practices had varied for educators. Strahan et al. (2017) conducted a study to understand the impact of students' understanding of growth mindset after learning foundational knowledge of different mindsets. The goal of the research was to capture the progression of students' knowledge of mindset concepts and academic ability while implementing mindset activities. The educators wanted to ensure that the students were aware of the choices available in their learning development and that the students understood what type of mindset would help them successfully progress academically. The students were introduced to the concept of fixed and growth mindsets, they had written reflections on their mindsets, and the teachers periodically held mindset discussions with the participating students. In the end, the researchers were able to document what mindset activities were integrated into seven language arts classes and the results of those activities. Although many of the students were able to explain the correlation between mindset and learning, some students were not able to apply those concepts to further their learning process (Strahan et al., 2017).

Although the previously stated studies have examined the relationship between mindset and goal setting, mindset and student performance and mindset and teacher achievements, there is literature lacking in studies examining teachers' sustainability of growth mindset concepts in instructional practices. The study conducted by Strahan et al. (2017) provided a factor that contributed to the development of this study's key problem. Strahan et al. (2017) stated challenges still exit in the ability to practice mindset concepts with students. There are some students who lack the ability to consistently progress academically following the implementation of mindset practices within the classroom (Cook et al., 2019; Mofield and Parker-Peters, 2018 Strahan et al., 2017). Even though teachers were employing mindset practices in their classroom, the inability of students to progress academically was an element that drove the purpose of this study. Exploration of this study's key problem was needed because the findings from this study identified a potential systematic approach to achieve consistency in effective instructional procedures.

\section{Theoretical framework}

Influenced by Weiner's work in the 1960s, Dweck (2017) produced data that outlined learned helplessness. Characteristics of learned helplessness assisted in the identification of factors about cognitive motivational processes regarding students' learning abilities. The concept of learned helplessness aided in the explanation of inept awareness of control (i.e. self-belief) that students had over their intellectual abilities (Gupta, 2013). In the mid-1980s, the link between self-belief and intelligence initiated mindset theory (Dweck, 2017).

Concepts found in motivation and attribution theories were utilized to develop mindset theory (Dweck, 2018). The foundational belief of mindset theory is that individuals construct 
JRIT

15,1

28

a viewpoint about their intellectual abilities (King, 2017). Fixed and growth are two perceived intelligences that have been established in mindset theory (Haimovitz and Dweck, 2016). Depending on the individual's perception, their actions and behaviors reflect efforts toward achievement (Haimovitz and Dweck, 2016). Mindset theory also explains that the two perceived intelligences can change and function in opposition to each other (Rattan et al., 2015).

Dweck's (2017) mindset theory focuses on perceptions of ability that lead to various levels of achievement in multiple areas such as education, sports and relationships. Mindset development was introduced because psychologists believed that willpower should be placed in people's own hands (Gupta, 2013). Those who use willpower to proceed amid failure may learn how to cultivate efforts that could lead to achievements (Davis, 2017). Failure does not necessarily need to be accepted, as it is possible to change mindsets to achieve success (Dweck, 2017).

\section{Purpose statement and research questions}

The purpose is to explore secondary teachers' (9-12) perspectives on sustaining the implementation of growth mindset concepts within instructional practices. In this study, insights and experiences were gathered from multidisciplinary secondary teachers. In addition, an exploratory approach was utilized to delve into uncharted areas of the phenomenon (Yin, 1981). The research questions that guided this study were:

$R Q 1$. What are the perspectives of secondary teachers (grades 9 through 12) on the ability to implement and sustain growth mindset concepts in their curricular and classroom instructional practices?

$R Q 2$. What do secondary teachers (grades 9 through 12) perceive to be the barriers to sustaining growth mindset concepts in classroom instructional practices?

\section{Method and design}

Qualitative research is known to contribute data that include unique descriptions and interpretations of participants' personal experiences of phenomena (O'Brien et al., 2014). An exploratory case study was chosen for this study over other qualitative designs because a case study has a more natural approach to understanding a phenomenon (Stake, 1978). The design allowed the researcher to focus on obtaining secondary teachers' lived experiences which were collected through structured interviews and a semi-structured focus group.

\section{Participants}

The sample for this study included seven public secondary teachers who varied in gender, subject area and grade level (see Table 1). Purposive sampling was used to recruit secondary teachers who were employed in a school district located in the west-central region of a southern state and had at least one growth mindset training or professional development. The participants were obtained from four out of the five secondary schools in the Internal Review Board (IRB)-approved school district.

\section{Data collection}

In total, seven participants from the four secondary schools partook in a 30-40 minute structured interview that was followed-up with a member checking process. Four of the seven initial participants joined the 20 minute semi-structured focus group. The duration of the data collection process was approximately three weeks. 
Interviews. The face-to-face interviews were a structured process containing 10 openended questions which allowed the participants to share their lived experiences and perspectives on sustaining growth mindset concepts in instructional practices. The interviews were held in the participant's classroom or a private meeting room at the local public library. Interviews were conducted with each participant individually. A predeveloped interview protocol was used to ensure each interview was implemented with fidelity (see Appendix 1). The interview was audio-recorded for accuracy. Google Voice Typing was employed to transcribe the participants' responses from the audio-recorded interviews. A copy of the transcribed interview was then sent to the corresponding participants for member checking. All participant responses were transcribed within $24-48 \mathrm{~h}$ of the interview and then emailed to the intended participant.

Focus group. For data triangulation, a face-to-face focus group was scheduled after the completion of the interview process. Triangulation provides results that are significant, comprehensive and can increase the validity of data (Wilson, 2016). The focus group was semi-structured and loosely driven by three questions to guide the discussion. A predeveloped focus group protocol was used to ensure that the direction of the focus group was clear to the participants (see Appendix 2). The focus group discussion was audio-recorded for accuracy and later transcribed for the data analysis process. The semi-structured process allowed the participants to openly discuss their insights and opinions relevant to influences and barriers about sustaining growth mindset concepts, a psychological approach, in instructional practices.

\section{Procedure for data analysis}

The data analysis followed the data collection process. The analysis included an inductive coding and categorization process. Initially, the interviews and focus group responses were colored-coded to identify responses relevant to the interview and focus group questions. Next, the color-coded details were categorized into groups to identify the similarities and differences between the participants' responses. Lastly, the categorized groups were then analyzed for common themes. The major themes that were developed from the data reflected recurring experiences and perspectives between the participants which aligned with the research questions.

\section{Findings}

The coded themes that were produced after data analysis could have a meaningful impact on the field of education. The following themes were identified: embed growth mindset practices in daily classroom instruction, communicate verbal affirmations to students and implement growth mindset learning tasks, allow students to experience academic successes and failures and teachers should receive continual support and professional development. The themes

\begin{tabular}{llclr}
\hline Participant & Gender & Years teaching & Subject & Grade level(s) \\
\hline P1 & Male & 10 & Economics & 10,12 \\
P2 & Female & 3 & Reading & 9,12 \\
P3 & Female & 13 & Reading & $11-12$ \\
P4 & Male & 16 & Art & $9-12$ \\
P5 & Female & 2 & English & 12 \\
P6 & Female & 18 & Math & $9-12$ \\
P7 & Female & 9 & Science & $9-12$
\end{tabular}

Table 1.

Overview of participants' demographics 
JRIT

15,1

also allude to possible approaches to the topic of this study which could have a meaningful impact in the field of education.

\section{Theme 1: embed growth mindset practices in daily classroom instruction}

The participants' responses consistently included that growth mindset concepts should become part of the classroom norm through daily instruction. Daily commitment to growth mindset concepts can support continuous engagement in the concepts (Schmidt et al., 2017). When growth mindset skills and concepts are a staple in daily classroom instructional practices, academic successes could be maintained (Zurawski and Mancini, 2016).

Participants' responses included that teachers were able to be consistent by being mindful in including growth mindset concepts during daily instruction so that the concepts would become part of the classroom's practices. Participant 1 stated, "Continuously engaging in the work. I like intertwining the skills that we're doing in class. You can see that it's part of what they do. It's just part of the daily routines." Participant 3 reflected, "Students continuously engaging in growth mindset concepts during instruction realize that they can work towards growing in whatever they are doing." Further support for this theme showed how teachers need to be cognizant of implementing growth mindset concepts in daily instruction to sustain growth mindset practices. Participant 6 articulated:

Just being aware that you're doing it in your daily instruction. I say in everything we do. Algebra 2 is really hard for students. So, every day I try to introduce the [growth mindset] concepts. I guide them through something they can do so that they can apply it to the challenging problem. So, every day.

Participants recognized the value and result of embedding the growth mindset concepts in their daily instruction. When growth mindset practices become part of daily instruction, the students, unbeknownst to them, would be continuously engaged in those concepts.

\section{Theme 2: communicate verbal affirmations to students and implement growth mindset learning tasks}

The combination of both verbal affirmations of effort and growth mindset learning tasks may contribute to the sustainability of growth mindset concepts within instruction. Although each participant was not practicing both, the data analysis revealed that verbal affirmations and growth mindset learning tasks were needed for sustainment. Growth mindset's conceptual framework was developed from motivation and attribution theoretical concepts (Dweck, 2018).

Foundational knowledge about the growth mindset framework supported the findings from this study that there was a need for both verbal affirmation and learning tasks to sustain growth mindset concepts within classroom instruction. Participant 5 articulated, "But it's not just saying be positive; it's not ordering them to be a certain way or negating their feelings. It's telling them, it's showing them through scenarios that it's possible." Participant 3 expressed that she no longer placed grades on her students' tests. While students were completing their assessments, participant 3 verbally stated to the class to keep giving her their best effort, encouraging her students to continue moving towards their goal.

The participants' related experiences pertaining to the implementation of both verbal affirmations and learning tasks that would allow students to continuously practice growth mindset concepts within instruction. If the instruction is absent of both verbal affirmation and growth mindset learning tasks, learning achievement barriers may occur.

\section{Theme 3: allow students to experience academic successes and failures}

Conclusions from the data presented an outlook on sustaining growth mindset concepts in daily instruction should include opportunities for academic successes and failures to render 
possibilities for progressive struggles. Progressive struggles allow students to struggle with new ideas and concepts to practice a growth mindset and achieve learning growth (Polirstok, 2017). Participant 6 commented, "Not only do you have to give them the self-confidence to do it, they need to taste success," and participant 3 concluded, "Let them know it's okay to make mistakes and fail because that's how you grow."

Participants explained that without the students being able to acknowledge their academic successes and failures, students would encounter at least two experiences. Either the students would believe that they did not have to apply any effort to succeed academically, or students would not give any effort due to excessive academic failures. Participant 1 gave a clear example:

All feedback [academic successes and failures], albeit specific, needed to be experienced by students. Key component to growth mindset is just understanding that with effort will come growth especially if you focus that effort in a productive way. So that really hits at the idea of the growth process.

Review of the participants' perspectives imparted the idea that teachers would need to set a precedence to foster a culmination of opportunities within instruction that produces student learning encounters resulting in possible academic successes and failures. Ultimately, classroom instruction that contains academic success without failure, and vice versa, may become an obstacle to maintaining growth mindset concepts within instructional practices.

\section{Theme 4: teachers should receive continual support and professional development}

An overwhelming agreement between the participants was that teachers needed support via administration, parents and professional development workshop opportunities to continue the implementation of growth mindset concepts within instruction. Impediments may be developed in sustaining growth mindset concepts within instruction if support is not given. Holdsworth and Maynes (2017) documented, "Support[ing] teachers in their roles as agents of positive change will inevitably contribute to ongoing and sustainable innovation in schools" (p. 691). Support to continue implementing growth mindset concepts in instruction can be provided in various ways including ongoing professional development, grade-level school administrative-driven workshops, single-session workshops and in-class peer observations. Participant 2 declared, "There should be more trainings. 100\%. Because I would love to do more with this [implementing growth mindset] and dig deeper into this [understanding how to instruct using growth mindset concepts]." Seaton (2018) suggested educational leaders engage teachers in multiple growth mindset trainings. The results from such trainings may detail a systematic change in teachers' growth mindset practices which progressively impacted students' academics. Participant 4 specified, "Support helps a lot. Support would be from the parents. When the parents are supportive, that's another resource that helps sustain that type of motivation." Participant 7 conveyed, "To have admin be there and support you, like they do now, that's awesome."

What was exhibited robustly throughout the data included the various supports from administration and ongoing professional development needed for teachers to continue to implement and influence the sustainment of growth mindset classroom instructional practices. Additionally, ongoing professional development may increase teachers' reflection on current instructional approaches and how growth mindset practices may influence student academic achievement. The revealed experiences outlined the perception that teachers may be more successful in sustaining growth mindset concepts within classroom instruction when they are provided with continued teacher support and professional developments.

\section{Discussion}

To sustain growth mindset concepts within instruction, secondary teachers should embed growth mindset practices in daily classroom instruction, communicate to students verbal
Secondary teachers sustaining growth mindset 
JRIT

15,1

affirmations and implement growth mindset learning tasks, allow students to experience academic successes and failures and self-advocate for continual support. Each of the four approaches noted above addresses the key problem and research questions providing teachers with the opportunity to effectively and continually employ growth mindset concepts in instruction to progress students academically. Each of the four approaches echoes the need for teachers to support their students in establishing academic motivation, developing resiliency to academic progress and maintaining belief in intellectual abilities (Aditomo, 2015; Boylan et al., 2018; Mofield and Parker-Peters, 2018). Furthermore, the four approaches should be connected to the teacher's daily learning practices to produce an effective and engaging learning environment. Ideas and concepts presented in growth mindset may provide educators with effective instructional tools for students' progression of learning (Seaton, 2018). When growth mindset practices are facilitated successfully by the teacher in the classroom setting, academic progression of students may occur (Lysniak et al., 2019).

The findings highlighted the significance of fostering purpose to execute actions (motivation) and offer or discover explanations of causation (attribution), which are the foundational aspects in growth mindset theory. Substantiated experiences that include the findings from this study can be facilitated and practiced by teachers to establish and retain opportunities for students' educational progression. The four major themes detailed possible approaches to the identified key problem of the study as well as offering an effective psychological teaching tool (growth mindset concepts) for secondary school educators. Concepts found in growth mindset practices could attribute to academic achievement (Degol et al., 2018; Hoyert et al., 2019; Polirstok, 2017). However, sole awareness of this study's findings may not be sufficient in sustaining growth mindset concepts in instructional practices. In conjunction with awareness, secondary teachers may achieve sustainment of growth mindset practices in instruction through the consistent application of the four themes (approaches). Continuous implementation of any practice forms a routine which contributes to sustainable behaviors (Ragland, 2015).

\section{Implications for practice}

The results of this study may provide awareness and need for perpetual practice of growth mindset concepts in daily classroom instruction. Qualitative case studies provide enriching experiences and may become relevant to the field of education due to the studies' distinguished effects to identify possible unique experiences (Dowling et al., 2016). This exploratory case study was initiated to gather authentic experiences of secondary teachers as they relate to sustaining an effective psychological instructional tool that can influence students' academic progression. In this era of educational reformation, all educators are accountable to take measures that can result in student academic progression (Nordgren, 2015). Although accountability in education mostly focuses on high-stakes testing and student retention, on a smaller scale, procedures that can influence consistency in effective classroom instructional practices should also be examined as a productive measure of accountability. Teachers who are accountable for their classroom practices can increase the quality of their instruction (Nordgren, 2015). The shared experiences provided in-depth perspectives on approaches that could be utilized by educators to manifest possibly needed changes to the classroom environment to impact student academics.

Field of education. This study presented authentic experiences of the study participants that may provide the educational field with opportunities to gain an understanding of sustainable instructional growth mindset practices. The field of 
education continuously confronts barriers to providing students with quality education (Piyaman et al., 2017). Overall, the results from this study can provide the field of education a broader understanding of a psychological intervention to maintain student academic success through growth mindset concepts and practices which differ from the multitude of academic interventions or behavioral interventions that already exist in the field.

Educational leaders. The findings of this study may offer resources and insights to educational leaders by developing the awareness of those they lead on sustaining effective growth mindset classroom instructional methods at the secondary level. Educational leaders may guide their schools to achieve academic successes using their established curriculum and at the same time allowing secondary school teachers to implement the four major themes presented in this study. Specifically, school leaders would need to become familiar with the instructional capacity of sustaining growth mindset principles to increase student confidence in their growth of learning. With leaders developing an understanding of sustaining growth mindset practices in instruction, they would be able to bridge the gap between comprehending the foundational knowledge of growth mindset and how teachers can present instructional practices that include growth mindset concepts.

Teachers. Teachers who are seeking an instructional systematic process that may prolong an efficient instructional change and contribute to student academic success should consider strategically practicing with fidelity each of the major themes for growth mindset instructional practice identified in this study. Schmidt et al. (2015) supported the concept of teachers who instruct using growth mindset strategies which could increase their students' academic performances. Exposure of teachers' experiences on sustaining growth mindset concepts in instruction can inspire current and future teachers to reflect on existing instructional processes. The four themed recommended approaches offer transformational learning techniques that may assist teachers in their classroom instructional design and development of classroom curriculum.

\section{Limitations and future research}

Limitations were encountered during this exploratory case study. First, data could only be retrieved from school administrators who provided approval. Four out of the five secondary schools consented to the approval stipulation. Therefore, complete coverage of the school district's secondary schools was not represented in the study. The next limitation was recognized during the selection of the population process. Due to electing the electronic mailing (email) strategy to circulate the study to possible participants, the researcher was required to wait on potential respondents. As a result, this limitation instituted interactive hardship during the recruitment process. The study was limited to only seven participants due to the internal procedures and permissions granted at the study location. The participants may not fully represent the total population of educators. A final limitation of this study, which is also a common limitation for qualitative research, is the general nature of the findings.

Further exploration may be considered in identifying approaches for sustaining growth mindset concepts within classroom instruction in various content areas for grades $K-8$. Analyzing of the similarities and dissimilarities on the growth mindset sustainment processes between all grade levels ( $K-12)$ may then be employed to further develop and refine the approaches. The interview and focus protocols from this study can aid researchers in future studies (see Appendixes 1 and 2). Additionally, further examination in the suggested area may uncover vertical and horizontal differentiation among techniques for sustaining growth mindset concepts in instruction. 
JRIT

15,1

\section{Conclusion}

The purpose of this study was to address the key problem of teachers insufficiently sustaining effective instruction when including growth mindset practices. Previous studies have indicated that growth mindset concepts can attribute to student academic achievement (Degol et al., 2018; Hoyert et al., 2019; Polirstok, 2017). Findings in this study were supported by several growth mindset research studies which included concepts of establishing academic motivation, developing resiliency to academic progress and belief in intellectual abilities (Aditomo, 2015; Boylan et al., 2018; Mofield and Parker-Peters, 2018). However, sustaining effective instructional tools that include growth mindset concepts within classroom instruction remained a concern (Seaton, 2018).

This case study focused on obtaining secondary school teachers' perspectives on sustaining growth mindset concepts within instruction. The four themes developed from the study's data - embedding growth mindset concepts within daily classroom instruction, verbal affirmations to students with growth mindset learning tasks, experiences for academic successes and failures and continual teacher support and professional development - offer responses to the research questions and may provide educators with possible approaches to sustaining growth mindset concepts within classroom instruction. Educators who seek to commit efforts that may substantiate an effective progressive academic classroom environment should implement all four themes. Additionally, all four themes can encourage sustainable instruction of growth mindset concepts that can influence the learning capabilities of both teachers and students.

\section{References}

Aditomo, A.A. (2015), "Students' response to academic setback: 'growth mindset' as a buffer against demotivation”, International Journal of Educational Psychology, Vol. 4 No. 2, pp. 198-222.

Armstrong, A.J. (2017), "Key aspects of rigour that improve classroom instruction", Australian Educational Leader, Vol. 39 No. 4, pp. 6-9.

Bates, P. (2016), “Growth mindset”, Access, Vol. 30 No. 4, pp. 28-31.

Blackwell, L.S., Trzesniewski, K.H. and Dweck, C.S. (2007), "Implicit theories of intelligence predict achievement across an adolescent transition: a longitudinal study and an intervention", Child Development, Vol. 78 No. 1, pp. 246-263.

Boylan, F., Barblett, L. and Knaus, M. (2018), "Early childhood teachers' perspectives of growth mindset: developing agency in children”, Australasian Journal of Early Childhood, Vol. 43 No. 3, pp. 16-24.

Cerasoli, C.P., Nicklin, J.M. and Ford, M.T. (2014), "Intrinsic motivation and extrinsic incentives jointly predict performance: a 40-year meta-analysis”, Psychological Bulletin, Vol. 140 No. 4, pp. 980-1008.

Clemens, E.V., Klopfenstein, K., Lalonde, T.L. and Tis, M. (2018), "The effects of placement and school stability on academic growth trajectories of students in foster care", Grantee Submission, Vol. 87, pp. 86-94.

Cook, D.A. and Artino, A.R. (2016), "Motivation to learn: an overview of contemporary theories", Medical Education, Vol. 50 No. 10, pp. 997-1014.

Cook, D.A., Gas, B.L., Farley, D.R., Lineberry, M., Naik, N.D., Cardenas Lara, F.J. and Artino, J.A.R. (2019), "Influencing mindsets and motivation in procedural skills learning: two randomized studies", Journal of Surgical Education, Vol. 76 No. 3, pp. 652-663.

Cooper, J.T., Hirn, R.G. and Scott, T.M. (2015), “Teacher as change agent: considering instructional practice to prevent student failure", Preventing School Failure, Vol. 59 No. 1, p. 1.

Davis, V.W. (2017), "Error reflection: embracing growth mindset in the general music classroom", General Music Today, Vol. 30 No. 2, pp. 11-17. 
de Kraker-Pauw, E., Van Wesel, F., Krabbendam, L. and Van Atteveldt, N. (2017), “Teacher mindsets concerning the malleability of intelligence and the appraisal of achievement in the context of feedback", Frontiers in Psychology, Vol. 8, pp. 1-13.

Degol, J.L., Wang, M.T., Zhang, Y. and Allerton, J. (2018), "Do growth mindsets in math benefit females? Identifying pathways between gender, mindset, and motivation", Journal of Youth and Adolescence, Vol. 47 No. 5, pp. 976-990.

Dowling, R., Lloyd, K. and Suchet-Pearson, S. (2016), "Qualitative methods 1: enriching the interview”, Progress in Human Geography, Vol. 40 No. 5, pp. 679-686.

Dweck, C.S. (2006), Mindset: The New Psychology of Success, Random House, New York, NY.

Dweck, C.S. (2016), Mindset: The New Psychology of Success, Ballantine Books, New York, NY.

Dweck, C.S. (2017), "The journey to children's Mindsets-and beyond", Child Development Perspectives, Vol. 11 No. 2, pp. 139-144.

Dweck, C.S. (2018), "Reflections on the legacy of attribution theory", Motivation Science, Vol. 4 No. 1, pp. 17-18.

Ellison, D.W. and Woods, A.M. (2016), "Deliberate practice as a tool for effective teaching in physical education", Journal of Physical Education, Recreation and Dance, Vol. 87 No. 2, pp. 15-19.

Gupta, S. (2013), "QnAs with Carol S. Dweck", Proceedings of the National Academy of Sciences of the United States of America, Vol. 110 No. 37, p. 14818.

Gutshall, C.A. (2017), "Pre-service teachers' mindset beliefs about student ability", Electronic Journal of Research in Education Psychology, Vol. 12 No. 34, pp. 785-802.

Haimovitz, K. and Dweck, C.S. (2016), "What predicts children's fixed and growth intelligence mindsets? Not their parents' views of intelligence but their parents' views of failure”, Psychological Science, Vol. 27 No. 6, pp. 859-869.

Haque, M.F., Haque, M.A. and Islam, M.S. (2014), "Motivational theories - a critical analysis", ASA University Review, Vol. 8 No. 1, pp. 61-68.

Heider, F. (1958), The Psychology of Interpersonal Relations, Psychology Press, New York, NY.

Helbling, C. (2018), "Cultivate and sustain motivation”, Chemical Engineering Progress, Vol. 114 No. 7, pp. $40-45$.

Holdsworth, S. and Maynes, N. (2017), "But what if I fail?' A meta-synthetic study of the conditions supporting teacher innovation", Canadian Journal of Education, Vol. 40 No. 4, pp. 665-703.

Hoyert, M.S., Ballard, K. and O'Dell, C.D. (2019), "Increasing student success through a cocktail of cognitive interventions", The Journal of Scholarship of Teaching and Learning, Vol. 19 No. 1, pp. 128-134.

Katrein, J. (2016), "Student questions, conversations, and reflections", Ilinois Reading Council Journal, Vol. 45 No. 1, pp. 12-22.

King, R.B. (2017), "A fixed mindset leads to negative affect: the relations between implicit theories of intelligence and subjective well-being", Zeitschrift für Psychologie, Vol. 225 No. 2, pp. 137-145.

Liu, Y. and Hou, S. (2018), "Potential reciprocal relationship between motivation and achievement: a longitudinal study", School Psychology International, Vol. 39 No. 1, pp. 38-55.

Lysniak, U., Gibbone, A. and Silverman, S. (2019), "Effective teaching strategies for low-skilled students", Physical Educator, Vol. 76 No. 3, pp. 701-725.

Malin, J.R., Bragg, D.D. and Hackmann, D.G. (2017), "College and career readiness and the every student succeeds act”, Educational Administration Quarterly, Vol. 53 No. 5, pp. 809-838.

Malle, B.F. (2008), "Fritz Heider's legacy: celebrated insights, many of them misunderstood", Social Psychology, Vol. 39 No. 3, pp. 163-173.

Marzano, R.J. (2009), "Setting the record straight on 'high-yield' strategies”, Phi Delta Kappan, Vol. 91 No. 1, pp. 30-37. 
JRIT 15,1

Marzano, R.J. (2018), The Handbook for the New Art and Science of Teaching, Solution Tree, Bloomington, IN.

Mawer, J. (2014), "A simple use of Dweck's mindset theory", Australian Educational Leader, Vol. 36 No. 2, pp. 50-52.

Mofield, E.L. and Parker-Peters, M. (2018), "Mindset misconception? Comparing mindsets, perfectionism, and attitudes of achievement in gifted, advanced, and typical students", Gifted Child Quarterly, Vol. 62 No. 4, pp. 327-349.

Moran, P. (2015), "Reacting to crises: the risk-averse nature of contemporary American public education”, Policy Futures in Education, Vol. 13 No. 5, pp. 621-638.

Nordgren, R.D. (2015), "The age of accountability in education: modernist approaches to school reform", Journal of Research in Innovative Teaching, Vol. 8 No. 1, pp. 2-19.

O'Brien, B.C., Harris, I.B., Beckman, T.J., Reed, D.A. and Cook, D.A. (2014), "Standards for reporting qualitative research: a synthesis of recommendations", Academic Medicine, Vol. 89 No. 9, pp. 1245-1251.

Paunesku, D., Walton, G.M., Romero, C., Smith, E.N., Yeager, D.S. and Dweck, C.S. (2015), "Mind-set interventions are a scalable treatment for academic underachievement", Psychological Science, Vol. 26 No. 6, pp. 784-793.

Persky, A.M. (2014), "Cost-benefit of instructional strategies", American Journal of Pharmaceutical Education, Vol. 78 No. 8, pp. 1-2.

Piyaman, P., Hallinger, P. and Viseshsiri, P. (2017), "Addressing the achievement gap”, Journal of Educational Administration, Vol. 55 No. 6, pp. 717-734.

Polirstok, S. (2017), "Strategies to improve academic achievement in secondary school students: perspectives on grit and mindset", SAGE Open, Vol. 7 No. 4, pp. 1-9.

Ragland, R.G. (2015), "Sustaining changes in history teachers' core instructional practices: impact of "teaching American history" ten years later", The History Teacher, Vol. 48 No. 4, pp. 609-640.

Rattan, A., Savani, K., Chugh, D. and Dweck, C.S. (2015), "Leveraging mindsets to promote academic achievement: policy recommendations", Perspectives on Psychological Science, Vol. 10 No. 6, pp. 721-726.

Robinson, C. (2017), “Growth mindset in the classroom”, Science Scope, Vol. 41 No. 2, pp. 18-21.

Schaller, M., Kenrick, D.T., Neel, R. and Neuberg, S.L. (2017), "Evolution and human motivation: a fundamental motives framework", Social and Personality Psychology Compass, Vol. 11 No. 6, pp. 1-15.

Schmidt, J.A., Shumow, L. and Kackar-Cam, H. (2015), "Exploring teacher effects for mindset intervention outcomes in seventh-grade science classes", Middle Grades Research Journal, Vol. 10 No. 2, pp. 17-32.

Schmidt, J.A., Shumow, L. and Kackar-Cam, H.Z. (2017), "Does mindset intervention predict students' daily experience in classrooms? A comparison of seventh and ninth graders' trajectories", Journal of Youth and Adolescence, Vol. 46 No. 3, pp. 582-602.

Seaton, F.S. (2018), "Empowering teachers to implement a growth mindset", Educational Psychology in Practice, Vol. 34 No. 1, pp. 41-57.

Serdyukov, P. (2017), "Innovation in education: what works, what doesn't, and what to do about it?", Journal of Research in Innovative Teaching and Learning, Vol. 10 No. 1, pp. 4-33.

Sisk, V.F., Burgoyne, A.P., Sun, J., Butler, J.L. and Macnamara, B.N. (2018), "To what extent and under which circumstances are growth mind-sets important to academic achievement? Two metaanalyses", Psychological Science, Vol. 29 No. 4, pp. 549-571.

Stake, R.E. (1978), "The case study method in social inquiry", Educational Researcher, Vol. 7 No. 2, pp. 5-8. 
Strahan, D., Hansen, K., Meyer, A., Buchanan, R. and Doherty, J. (2017), "Integrating mindset interventions with language arts instruction: an exploratory study with seventh grade students", RMLE Online: Research in Middle Level Education, Vol. 40 No. 7, pp. 1-15.

Weiner, B. (2008), "Reflections on the history of attribution theory and research: people, personalities, publications, problems", Social Psychology, Vol. 39 No. 3, pp. 151-156.

Secondary teachers sustaining growth mindset

Weiner, B. (2014), "The attribution approach to emotion and motivation: history, hypotheses, home runs, headaches/heartaches", Emotion Review, Vol. 6 No. 4, pp. 353-361.

Wilson, V. (2016), "Research methods: triangulation", Evidence Based Library and Information Practice, Vol. 11 No. 1(S), pp. 66-68.

Winston, C.N. (2016), "An existential-humanistic-positive theory of human motivation”, The Humanistic Psychologist, Vol. 44 No. 2, pp. 142-163.

Yin, R.K. (1981), "The case study as a serious research strategy", Knowledge, Vol. 3 No. 1, pp. 97-114.

Zurawski, L. and Mancini, N. (2016), "Engaging your growth mindset for a successful school year", Perspectives of the ASHA Special Interest Groups, Vol. 1 No. 16, pp. 91-98.

\section{Further reading}

Richards, J. and Skolits, G. (2009), "Sustaining instructional change: the impact of professional development on teacher adoption of a new instructional strategy", Research in the Schools, Vol. 16 No. 2, p. 41.

\section{Appendix 1 \\ Interview protocol}

\begin{tabular}{ll}
\hline Study & Title of study \\
\hline Time of Interview & Start \\
\cline { 2 - 2 } Date & \\
Place & \\
Interviewer & 123456789101112131415 \\
Participant & \\
Teacher Name & \\
Subject Taught \\
Grade Level(s) \\
Years of Teaching
\end{tabular}

\section{Prior to interview:}

Verify that I have a signed consent form. If not, have the participant read and sign the consent form.

Give participants a copy of the interview questions and growth mindset definition to review in my presence for 3-5 min while I am setting up.

\section{Step 1: Introduction}

Script: Thank you for participating in this study. The questions I am going to ask are specific to you and the experiences you have encountered in the sustaining of growth mindset concepts within instruction. The interview is not intended to suggest that you should or should not be using growth mindset concepts within instruction for your teaching practices in the classroom. You are not being judged during this interview based on if you are implementing and/or sustaining growth mindset concepts in instruction within your teaching practices in the classroom. For this study, I need your answers to be 
JRIT

15,1

honest and for you not to respond to a question just because you think or feel it is what I, the researcher, would want to hear.

Step 2: Purpose of study

Script: This study is being conducted because I want to know (research question): What are the perspectives of high school teachers (grades 9 through 12) on the ability to implement and sustain growth mindset concepts in their curricular and instructional practices?

Step 3: Project description

Script: The purpose of this qualitative case study is to explore teachers' perceptions toward the sustainment of growth mindset concepts within instructional practices. Interviews will be conducted with teachers who have participated in one or more mindset training or professional development. The interview will be recorded for accuracy. The recording will be transcribed and coded (explain coding). As a way of checking for accuracy, I will provide you with a copy of your transcribed interview to view for accuracy. The data collected will be accessible to the researcher (me) and locked in a file cabinet or computer. The interview will take approximately thirty minutes. During the interview, my lack of conversational response is to avoid me influencing your responses.

For the purpose of this interview, there is no right or wrong answer. You will not be judged based on your responses. I want to collect honest data for my study. I am looking for your perception toward the sustainment of growth mindset concepts within instructional practices. Before starting, I will provide you with the definition of growth mindset and allow 1 minute of think time.

Are there any questions?

Step 4: Define growth mindset

Script: Growth mindset refers to the belief that there are no limits to ability, and with continuous efforts, success may be obtained. Those who practice a growth mindset believe that they will be able to put forth efforts that may progressively impact achievements. Efforts are then made to progress toward achievements continuously.

Step 5: Press record on the tape recorder

Step 6: Ask questions in the order that they appear

- How many growth mindset trainings or professional developments have you attended? Can you describe them?

- How would you define growth mindset concepts?

- Could you provide examples or explain some growth mind concepts?

- What is the difference between students being aware of growth mindset concepts and students continuously engaging in growth mindset concepts during instruction?

- What types of growth mind tasks or activities do you include in your daily or weekly instruction?

- How could growth mind concepts be sustained in instruction?

- What supports do you perceive are available or should be available to teachers to sustain growth mindset concepts within instruction?

- What do you perceive to be the barriers of being able to sustain growth mindset concepts within instruction?

- How are students receptive to engaging in continuous growth mindset concepts within instruction?

- Is there anything else you would like to share about the sustainment of mindset concepts in instruction?

Step 7: Conclusion of interview

Stop recorder. Time of interview End 
Script: This concludes the interview. I will email you the transcript of this interview within $24-48 \mathrm{~h}$ from today for you to review for accuracy. Please review the transcript within $24 \mathrm{~h}$ and email me with any needed corrections. Thank you again for participating in my study. I will send you a copy/link of my dissertation once it is published.

\section{Secondary teachers sustaining growth mindset}

\section{Appendix 2 Focus group protocol}

Study

Time of

Interview

Date

Place

Interviewer Maria Jorif

\# of

Participants

Start
Perspectives of secondary teachers on the sustainability of growth mindset concepts in instructional practices: An exploratory case study

Step 1: Introduction

Script: Thank you for participating in this study. The discussion during this focus group will be specific to you and the experiences you have encountered in the sustaining of growth mindset concepts within instruction. The focus group is not intended to suggest that you should or should not be using growth mindset concepts within instruction for your teaching practices in the classroom. The individuals in this group will not be judged during this focus study based on if the individuals in this group are implementing and/or sustaining growth mindset concepts in instruction within your teaching practices in the classroom. For this study, Ineed the focus group discussion to be honest and not provide responds just because the group thinks or feels it is what I, the researcher, would want to hear.

Step 2: Purpose of study

Script: This study is being conducted because I want to know (research question): What are the perspectives of high school teachers (grades 9 through 12) on the ability to implement and sustain growth mindset concepts in their curricular and classroom instructional practices?

Step 3: Explain the structure of the focus group discussion

Script: The focus group discussion will be semi-structured. I will begin the discussion with a question. However, the group is allowed to freely take the discussion in any direction just as long as the discussion stays on the topic of sustaining growth mindset concepts within instruction. The focus group discussion will last 15 minutes. If there is a lull during the discussion, any participant can turnover one of the discussion cards, and each participant can provide their perspectives on the statement written on the card. At the end of the 15 minutes, the researcher will end the focus group discussion unless the group is engaged in conversation. At that point, the researcher will wait until all experiences and responses have been shared, and then end the focus group session.

For the purpose of this focus group discussion, there is no right or wrong answer. You will not be judged based on your responses. The focus group discussion will be recorded for accuracy. The recording will be transcribed and coded. The data collected will be accessible to the researcher (me) and locked in a file cabinet or computer. During the focus group discussion, my lack of conversational response is to avoid me influencing your responses.

Are there any questions?

Step 4: Press record on the tape recorder

Step 5: Start timer

Step 6: Ask question 
JRIT

15,1

Script: Growth mindset is a psychological intervention, do mental concepts need to be understood to effectively sustain growth mindset concepts within instruction? In other words, do teachers need to understand how the brain works to effectively sustain growth mindset concepts within instruction?

Step 7: Conclusion of focus group

Stop recorder. Time of focus group End

Script: This concludes the focus group session. Thank you again for participating in my study. I will send you a link of my dissertation once it is published.

\section{Corresponding author}

Maria Jorif can be contacted at: mjorif@email.phoenix.edu

For instructions on how to order reprints of this article, please visit our website: www.emeraldgrouppublishing.com/licensing/reprints.htm Or contact us for further details: permissions@emeraldinsight.com 